\title{
Alguns Apontamentos Sobre as Relações de Poder e Controle nas Instituições PsiQuiátricas
}

\author{
Lecy Sartori ${ }^{1}$
}

\section{Resumo}

0 presente artigo pretende entender a relação que a sociedade brasileira tem com os doentes mentais, partindo de uma análise histórico-social da loucura. Assim, procurou-se examinar as formas de poder e controle instituídas em seu tratamento, que por um lado são impostas pelo saber médico psiquiátrico - encontrando-se em instituições como o próprio hospital psiquiátrico - e por outro, um novo modelo de tratamento oferecido para o doente mental, denominado de CAPs (Centro de Atendimento Psicossocial). 0 artigo ilustra algumas respostas obtidas pelo trabalho de campo realizado no Centro de Atendimento Psicossocial da cidade de Londrina, este com o objetivo de compreender as especificidades do lidar com o doente mental, assim como as constatadas relações de poder e controle que existem em seu tratamento.

Palavras-chave: Doente Mental, Política Publicas, Foucault: relação de poder e controle.

\section{Abstract}

This present article verifies how Brazilian society relates to mentally-ill patients, based on the perspective of a social-historical analysis of madness. The forms of power and control in their treatments were examined and considered. These are treatments imposed by the psychiatric knowledge of the physician in the psychiatric hospital or a new treatment model offered to mentally-ill patients in the so-called CAPs - the Psychosocial Service Centers. Some answers for understanding the specificities of mentally-ill patients care as well as for perceiving the relationships of power and control underlying their treatment were obtained through field research made in the Psychosocial Service Center of Londrina.

Keywords: Mentally-ill Patient, Public Policies, Foucault: the relationship of power and control.

\footnotetext{
${ }^{1}$ Graduada em Ciências Sociais pela Universidade Estadual de Londrina e-mail: lecy_sartori@hotmail.com
} 


\section{INTRODUÇÃo}

A loucura, da Antigüidade grega até os pré-socráticos era considerada um efeito dos capricho dos deuses ou produto de interferências sobrenaturais provocadas por entidades. Nesta época não havia uma concepção de "natureza humana" bem estruturada. Homero acreditava ser a loucura

um estado de desrazão, de perda de controle consciente sobre si mesmo, de insensatez, no sentido de que, sob a atê ['atê' para Homero tem o sentido de perda temporária de razão ou consciência], o homem perde, ou pode perder, o contato ordenado com a realidade física ou social (PESSOTTI, 1994, p.19).

Na época medieval, foi criada a Doutrina Demonista que acreditava ser a loucura fruto de uma possessão diabólica. Com a consolidação do poder do Cristianismo, todas as divindades foram consideradas 'pagãs' e seus seguidores considerados adoradores do demônio, hereges. Nesta época, o Cristianismo legitima, por meio de um discurso inflamado e condenatório contra pagãos e infiéis, sua intolerância religiosa e suas perseguições.

Ao longo do tempo, várias concepções de loucura foram elaboradas, surgiram novas classificações como, o modelo iatroquímico, do século XVI e XVII, que foi a primeira corrente científica a negar a doutrina demoníaca. Segundo esta vertente, as doenças resultavam das alterações dos sais no corpo. Foi somente a partir do século XVIII que se passou a observar as alterações fisiológicas e comportamentais.

No século XIX, surge o tratado de Pinel (ou Tratado Médico-Fisiológico sobre Alienação Mental), publicado em 1801 e republicado em 1809. Já no prefácio de sua obra, Pinel define a loucura como passional e a alienação como não tendo origem orgânica. Mostra a importância da observação para que não se confunda os diagnósticos.

Por meio da observação detalhada é possível ordenar os sintomas, que se apresentam de maneira caótica. E deste modo classificá-los e defini-los. "Pinel entende a loucura, [...] como [sendo uma] lesão do intelecto ou da vontade, embora manifestada por sintomas orgânicos e comportamentais" (PESSOTTI, 1999, p. 57). Na segunda parte do tratado, Pinel ilustra a loucura identificando-a a alterações físicas que podem ser observadas pelos sinais externos causados pelas diferentes lesões do intelecto.

Do ponto de vista prático, Pinel adota uma posição moralizante quando referese aos doentes e suas condutas. Por exemplo, quando o médico observa a loucura como causadora de 'maus hábitos' na esfera sexual, esta deve ser tratada com "processos repressivos". Quando a reforma dos costumes imposta aos pacientes não trazia resultados positivos, o louco devia ser confinado, pois esta esfera sexual com distúrbios - segundo 
esta teoria, uma das características físicas da alienação - impossibilita o processo de tratamento do doente mental.

Pinel, em seu tratado, aponta como uma das causas da loucura a "imoralidade", pois para este a loucura seria "excesso e desvio, a ser corrigido pel a mudança de costumes, mudanças de hábitos" (PESSOTTI, 1994, p. 156). Por isso, Pinel pode ser considerado o precursor do tratamento moral, que tinha como meta a reeducação do paciente, enquadrando-o dentro dos padrões éticos da sociedade. Este tratamento, normalmente, fazia uso de práticas violentas, como o emprego da força, intimidações, privações, ameaças, etc., com o intuito de reprimir os impulsos dos doentes.

A prática de retirar os doentes mentais do convívio social para colocá-los num lugar específico surge em um determinado período histórico. No século XVII, os hospícios proliferam e abrigam conjuntamente os doentes mentais e os marginalizados de outras espécies. 0 tratamento que essas pessoas recebiam nas instituições costumava ser desumano, sendo considerado pior do que o recebido nas prisões.

A Europa do século XVII recolhia os seus loucos e os depositava em instituições denominadas asilos. Posteriormente, foram criadas instituições hospitalares normalmente filantrópicas - que acolhiam e tratavam os loucos juntamente com outros doentes. Os espaços destinados aos loucos (dentro dos hospitais) eram chamados de hospícios e quem cuidava destas instituições eram, em geral, pessoas sem formação médica, na maioria dos casos, religiosos. Já os manicômios são instituições que surgiram no começo do século XIX para abrigar apenas doentes mentais e proporcionavam um tratamento médico especializado e sistemático.

Para Pessotti, o século XIX poderia ser chamado de século dos manicômios, por sua proliferação como hospitais direcionados para o tratamento do alienado. 0 que fica bastante caracterizado neste período é a conduta do médico organicista - diferente do tratamento moral proposto por Pinel, em que a presença do médico era essencial para o emprego do método terapêutico. Agora, a presença do médico é responsável pelo diagnóstico e prescrição dos meios físicos como: "fármaco, a ducha, o vomitório, o purgante" (PESSOTTI, 1996, p. 227).

Segundo Foucault, a internação de loucos como prática social é tipicamente moderna, isto é, nascida de uma dupla necessidade das sociedades industriais capitalistas emergentes. Por um lado, da necessidade de saneamento e ordenação do espaço urbano, através da distribuição e do controle sobre a circulação dos indivíduos; por outro, da necessidade de disciplinarização dos corpos e mentes desses indivíduos, através da criação e proliferação de instituições disciplinares (PASSOS, 2003, p. 5). 
A psiquiatria, no século XX, apresenta-se como um saber médico capaz de impor aos indivíduos o isolamento - não apenas físico, mas social. Ela submete os alienados à pedagogia moral com práticas violentas, considera-o perigoso e incapaz. 0 hospital se torna, nesta esfera, um instrumento médico. E é o médico que detém o poder de escolha sobre as condutas que vão ser empregadas no tratamento do doente. 0 médico está posicionado no alto de uma hierarquia que impossibilita aos outros profissionais prestarem apoio psicológico, social, familiar, etc. Desta forma, o tratamento do doente se limita a medicalização. Para Basaglia, a "psiquiatria é sempre opressiva. É uma maneira de propor uma problemática de controle social" (BASAGLIA, 1982, p. 13).

Hoje, é fácil notar que dentro do hospital os médicos possuem alto grau de autonomia. Isto significa que não estão submetidos a quase nenhum mecanismo de controle. Os médicos detêm muito poder dentro dessas organizações. Quando falamos de poder, devemos sempre lembrar que ele é relacional, ou seja, está presente nas relações sociais. "Para Foucault (1995), o exercício do poder consiste em conduzir condutas e em ordenar probabilidades. Governar entendido como estruturar o eventual campo de ação dos outros. 0 poder é um ato; é algo usado ou exercido. 0 poder só existe em ato, é um modelo de ação de alguns sobre os outros" (apud CECíliO, 1999, p. 318).

Foucault permite pensar o poder como ato "que se apóia em estruturas permanentes"(apud CECílio, 1995, p. 320). Isto é, como ato que está alicerçado em instituições sociais e políticas concretas. Desta forma, a relação de poder permite um agir com relação à ação do outro, quer dizer, a relação de poder é condição e efeito que se materializam dentro de estruturas permanentes. Aquele que detém o poder, também detém 'modalidades instrumentais', ou seja, mecanismos de controle como regras, ameaças, etc., que são encontrados nas instituições.

No Brasil, a loucura permaneceu silenciosa por muito tempo. No século XVIII, o país era extremamente rural, suas capitais eram pouco habitadas, a economia era auto-suficiente (com produções basicamente domésticas). A loucura surge nas ruas, depois de ser ignorada por quase trezentos anos. Aqui também ela aparece, como alguns séculos antes na Europa, junto com os marginais e é considerada um obstáculo ao crescimento econômico, perturbadora da paz, ociosa e desordeira.

Essas enfermarias não comportavam todos os alienados que estavam nas ruas. Assim, os que não ficavam nas Santas Casas, eram mandados para as prisões junto com os arruaceiros, condenados, criminosos e bêbados, onde eram todos maltratados.

As construções destas instituições tinham como objetivo impedir o livre trânsito dos loucos pelas ruas das cidades, pois a população alegava que os doidos ameaçavam a paz e a ordem social. E contra os maus tratos que sofriam os loucos, a recém-criada 
Sociedade de Medicina se junta à população reivindicando tratamentos mais adequados, já em prática na Europa. Mesmo com todas as manifestações, a função da psiquiatria se limitava a remover os loucos da rua, a excluí-los colocando-os em lugares destinados a este fim, e a dar-lhes abrigo. Nesta época, os médicos eram poucos nas instituições e sua influência na parte administrativa era restrita.

Ao pensarmos a reforma psiquiátrica, o movimento antimanicomial e todas as transformações ocorridas com relação ao doente mental, é necessário nos atermos ao importante papel da sociedade civil brasileira, que ressurge na década de 70 - e que aparece extremamente marcada pelo período autoritário do regime militar, que havia tido seu início em 1964. Neste ressurgimento, a sociedade civil, se mostra mais autônoma e capaz de se organizar contra o Estado. Esta tomada de posição de indivíduos ou grupos mobiliza diferentes setores da vida social, como movimentos sociais, associações, sindicatos, igrejas, universidades, partidos, imprensa. 0 retorno dos mecanismos democráticos (eleições livres, fim da censura, liberdade para organizar partidos, etc.) não foi capaz de fazer com que o Estado brasileiro produzisse políticas adequadas para suprir os problemas de exclusão e desigualdades sociais.

Uma conseqüência do posicionamento da sociedade civil como atuante, foi a necessidade de se construir espaços públicos, com a finalidade de promover discussões no interior de grupos a respeito dos seus interesses, incluindo até mesmo a luta por espaços de democratização da gestão estatal. Podemos classificar esta relação entre a sociedade civil e o Estado de duas maneiras: a primeira é caracterizada por relações mais formais, com a utilização da legislação existente, que possui objetivos e funções já preestabelecidos. Neste caso, o seu caráter é permanente ou estável, como é fácil observar nos conselhos gestores de políticas públicas, nas relações Estado - ONGs e também nos Orçamentos Participativos. A segunda forma se caracteriza por uma relação menos formalizada, que pode partir do Estado ou da sociedade civil, como por exemplo algumas relações Estado - ONGs, alguns movimentos sociais como o MST, etc. Estas relações possuem objetivos, funções e procedimentos variados que são definidos pelo grupo.

Para Habermas, a esfera pública seria "uma estrutura intermediária entre 0 sistema político, de um lado, e os setores privados do mundo da vida [...] a esfera pública retira seus impulsos de assimilação privada de problemas sociais que repercutem nas biografias particulares" (MAIA, 2002, p.157-158). Para o autor, a sociedade civil possui assim um papel fundamental, pois é ela que produz o discurso, fora da arena política, capaz de compreender os problemas específicos dos grupos e indivíduos. Desta maneira, podemos considerar os movimentos sociais como impulsos que revitalizam as práticas e as instituições democráticas. 
Habermas, ao definir a esfera pública como sendo o espaço da vida social no qual se forma a opinião pública, faz com que os dois conceitos - esfera pública e opinião pública - tenham sentidos convergentes, e assim esfera pública seria o termo intermediário entre a sociedade civil e o Estado, onde o público se organiza como portador da opinião pública.

Para Munõz (2003), a esfera pública em Hannah Arendt vai além do conceito habermasiano, que se limita à opinião pública. Em Arendt, o espaço público é aquele no qual os indivíduos podem exibir suas distintas pluralidades e demarcar fortemente suas posições. Neste sentido, para ela, o caráter espacial do público é fundamental, enquanto para Habermas o mais importante é o seu caráter instrumental, isto é, o de servir de meio para a institucionalização das demandas sociais. Arendt ainda continua, especificando o termo público, que para ela tem dois significados: primeiramente, diz respeito a tudo que pode ser visto e ouvido por todos e possui uma grande divulgação podemos dizer que o que pode ser visto e ouvido por todos seria a realidade. E o termo público pode também significar mundo, no sentido que as coisas são comuns a todos.

Quando falamos em atuação da sociedade civil e sua reivindicação por um lugar de participação dentro dos espaços públicos, estamos falando de uma busca de poder de participação nas decisões e na execução de políticas - claro que este poder de decisão da sociedade civil é limitado e restrito a políticas mais amplas, que sejam capazes de causar algum impacto na sociedade como um todo. Ao analisarmos esta relação de poder, no entanto, notamos a existência de mecanismos que impedem

a partilha efetiva do poder nesses espaços [...] [alguns] desses mecanismos têm origem em concepções políticas resistentes à democratização dos processos de tomada de decisão, outros se relacionam com características estruturais do funcionamento do Estado, [...] [como] o predomínio de uma razão tecno-burocrática, o excesso de 'papelada', a lentidão, a ineficiência, a 'falta de sensibilidade e despreparo' da burocracia estatal; a falta de recursos; a instabilidade dos projetos que resultam de parcerias com o Estado na medida em que estão submetidos à rotatividade do exercício do poder, a falta de transparência que dificulta 0 acesso a informação, etc (DAGNINO, 2002, p.283).

Tais mecanismos e suas exigências impedem assim uma maior participação da sociedade civil nos espaços públicos por meio da demanda de qualificação, tanto técnica como política. 0 indivíduo que representa um determinado setor da sociedade organizada, quando mantém contato com a formulação e discussão de políticas públicas, deve ter 
o domínio de um saber técnico especializado do qual os representantes da sociedade civil, especialmente os dos setores subalternos, em geral não dispõem. [...] um outro tipo de qualificação se impõe, o que diz respeito ao conhecimento sobre o funcionamento do Estado, da máquina administrativa e dos procedimentos envolvidos (DAGNINO, 2002, p.284).

$\mathrm{Na}$ década de 80, com o surgimento dos movimentos sociais que lutaram pela descentralização do poder e pela redemocratização, os atores sociais tiveram um papel importante na formulação das novas formas de organização das políticas públicas e, também, na crítica às normas estabelecidas pelas políticas sociais sedimentadas em estruturas seletivas, excludentes e setorizadas.

Um dos exemplos desta luta por direitos e transformações é a Reforma Psiquiátrica Brasileira, que teve seu início no final da década de 70, com uma greve na DINSAM - Divisão Nacional de Saúde Mental -, ocorrida em abril de 1978. A greve foi provocada por três estagiários de medicina, do Hospital Psiquiátrico D. Pedro II, que denunciaram o hospital por precárias condições de atendimento, violências, ameaças, agressões, estupros, trabalho escravo e mortes não esclarecidas de pacientes. Este quadro mobilizou os profissionais da área, que passaram a fazer reuniões e assembléias, utilizando espaços em sindicatos e entidades da sociedade civil. Desta maneira, surge 0 Movimento dos Trabalhadores em Saúde Mental (MTSM), que questionava as políticas de saúde mental vigentes neste período (FIGUEIREDO, 1999, p. 23). Este movimento é muito influenciado pelas idéias de Franco Basaglia, responsável pela reforma psiquiátrica italiana.

Segundo Maia, o Movimento dos Trabalhadores de Saúde Mental tinha como principais reivindicações melhores condições de trabalho nos manicômios, humanização do espaço hospitalar, a ampliação do quadro de funcionários especializados e o aumento do investimento do setor público na área de saúde mental. A partir do ano de 1982, 0 MTSM passa a ter como novos objetivos as reivindicações de: proibir a criação de novos leitos em hospitais psiquiátricos, a criação de serviços ambulatoriais, o controle das internações em hospitais particulares, "humanização e processos de reinserção social dentro dos asilos estatais, também com equipe multiprofissionais" (VASCONCELOS, 2002, p. 25). Em 1987, ocorreu o segundo encontro deste movimento: seu lema era "Por uma sociedade sem manicômios". Este contribuiu para tomada de consciência a respeito da substituição do modelo asilar brasileiro, (CONFERÊNCIA NACIONAL..., 2002).

Apresentado em 1989, o projeto de Lei Paulo Delgado - inspirado na legislação italiana - propôs mudanças na legislação psiquiátrica. 0 projeto Paulo Delgado só foi aprovado em 2001 e propõe a substituição gradativa dos tratamentos manicomiais 
(VASCONCELOS, 2002, p. 26). Ainda, neste ano, em Santos, foi implementado o novo modelo de assistência psiquiátrica. Em São Paulo, o governo municipal construiu um dos principais Núcleos de Atenção Psicossocial, influenciados pela experiência de Trieste, Itália. 0 serviço prestado era comunitário, portas abertas funcionavam 24 horas por dia, atendia-se a quase todas as demandas, contendo alguns leitos e era capaz de substituir os hospitais psiquiátricos.

A desospitalização foi responsável pela redução dos leitos em hospitais privados e públicos e pela criação de novos leitos em hospitais gerais destinados ao doente mental, assim como serviços de atenção psicossocial - CAPs, hospital-dia, hospital-noite, NAPs, CAPs núcleo e Centro de Atenção Psicossocial, serviços abertos (são o contrário do hospital psiquiátrico, que é fechado e opera através do internamento). Outros profissionais da área social e da saúde se juntaram à equipe multiprofissional.

No final da década de 80 ocorreu um significativo avanço das políticas públicas, entendendo-se por políticas públicas aqui as ações do Estado em resposta às demandas criadas pela sociedade (CUNHA, 2002, p. 12). Esta mesma década foi marcada por políticas sociais que adotavam estratégias reformistas.

Surge, na década de 1980, o movimento antimanicomial, que se caracteriza por uma busca de tratamentos alternativos ao doente mental, como assistência extrahospitalar e multidisciplinar, mas também reivindicações de direitos, de exercício da cidadania e de emancipação. A questão mais debatida, pelo movimento antimanicomial seria a questão das representações simbólicas do doente, ou seja, propôs-se uma mudança nos padrões culturais. Ao invés de negar as diferenças ou dar proteção aos excluídos, deve-se buscar os direitos de cidadania que respeitem as diferenças.

Como se procurou mostrar, no decorrer da segunda metade do século XX ocorreram mudanças técnicas e sociopolíticas que contribuíram para a inversão do tratamento com relação ao doente mental, antes caracterizada por grandes instituições carcerárias repressivas e hoje em busca de uma atenção mais aberta junto à comunidade. A idéia de atenção à saúde mental deve ser local e acessível, buscando atender às múltiplas necessidades dos indivíduos, utilizando-se de métodos eficientes para obter a emancipação das pessoas portadoras de distúrbios mentais. Foi com este pensamento que no ano de 1989, em São Paulo e em Santos, implantaram o primeiro NAPs (Núcleo de Atenção Psicossocial). Esta iniciativa, inspirou vários Estados brasileiros à promoverem serviços alternativos ao asilamento, e foi considerado uma grande experiência que levou a criação, posteriormente, dos Centros de Atenção Psicossocial (VASCONCELOS, 2002, p. 26).

Este trabalho buscou refletir sobre o louco e sobres as condutas direcionadas a 
estes durante a história, procurando entender as relações de poder e controle que existem em seu tratamento, como vemos hoje no exemplo de tratamento oferecido pelo CAPs. A criação da instituição CAPs como uma alternativa ao tratamento do doente mental ainda é muito recente, mas possui seus méritos, entre os quais se pode apontar justamente o que motivou este trabalho: a possibilidade de se pensar o doente mental - que é sempre escondido, mascarado, distanciado. A partir do trabalho de campo, foi possível observar relações de poder e controle nesta instituição.

De acordo com Foucault, só o fato da CAPs ser uma instituição já implica relações de poder em seu cerne. 0 autor, em suas análises, afirma que toda relação social seria uma relação de poder. Assim, parece-nos possível sustentar, seguindo as análises de Foucault, que todas as práticas institucionais supõem relações de poder. Essas relações de poder geram saberes sobre seus objetos, exercício e efeitos, resultando num regime de poder que pode ser estendido a outras instituições e ao conjunto social. Foucault, analisando as práticas médicas, psiquiátricas, jurídicas, sexuais, carcerárias etc., descobriu pontos comuns no exercício do poder estendidos ao corpo social que determinaram estratégias ou dispositivos de exercício do poder ao longo da história da humanidade (ou modos de dominação, ou processos de institucionalização ou ainda técnicas de sujeição) (Foucault, 1991:30; 1988:182). Como resume Bisneto:

Para Foucault, o poder não está possuído e muito menos é propriedade de uma classe social. 0 poder não é tópico, é dinâmico, existe enquanto se exerce. As formas de dominação não são naturais, nem contratuais: são constituídas como técnicas de ação sobre as ações dos outros e determinadas historicamente na sociedade. Portanto existem vários tipos de exercício do poder e sua análise não pode ser diretamente derivada do funcionamento da Economia, do Direito ou da Cultura. 0 poder seria segundo o vocábulo institucionalista (não foucaultiano), 'transversal' (BISNET0, 2002, p.314).

E conclui: "É através da análise das práticas sociais que se estabelece uma analítica do poder, isto é, uma crítica aos diferentes regimes de poder, e uma possibilidade de reversão histórica das formas de dominação" (apud BISNETO, 2002, p. 314-5). Portanto, no presente trabalho, procurei mostrar como as condutas oferecidas pelo CAPs também se traduzem em relações de poder, como se pode depreender do exemplo de controle do CAPs sobre o paciente quando acontece deste não comparecer ao tratamento: o CAPs tem um sistema chamado de busca ativa, ou até mesmo a medicação de depósito (quando o paciente não toma a medicação, esta é administrada por via injetável). Também podemos citar o controle de atribuições, que compreendem relações de diferenciação como status médico, a hierarquia médica, a definição do diagnóstico, qual a medicação utilizada, quando o paciente vai receber alta etc. 
0 CAPs, é preciso frisar, está construindo mecanismos que servem para conter este poder médico, como a equipe multidisciplinar. Mas como a instituição CAPs é recente, esta equipe não funciona plenamente. Este quadro é agravado pelo fato de que a transmissão deste saber médico nas universidades ainda se mostra hierarquizada. É certo que existem iniciativas profícuas na direção de alterar esta situação. Mas é forçoso constatar que, mesmo entre as propostas e ações mais "progressistas", ainda impera, como se pode constatar por meio da pesquisa empírica realizada em Londrina, um elevado grau de controle, manipulação e discriminação do doente mental. Sabemos que as transformações das práticas e saberes sociais ocorrem paulatinamente, às vezes ao longo de séculos. Talvez o estudo sério e compromissado da questão possa ajudar não apenas a iluminar o tema, mas também, ao conferir-lhe relevo, contribuir para uma aceleração deste movimento na direção da mudança social.

\section{REFERÊNCIA}

ARENDT, Hannah. A condição humana. Rio de Janeiro: Forense Universitária, 1981.

BASAGLIA, Franco. A psiquiatria alternativa: contra o pessimismo da razão, o otimismo da prática. São Paulo: Brasil Debates, 1982.

BISNETO, José Augusto. A análise institucional no processo de renovação do serviço social no Brasil. In: ROSA, Lúcia Cristina dos Santos; PEREIRA, Ivana Carla Garcia; BISNETO, José Augusto; VASCONSELOS, Eduardo Mourão (Org.). Saúde mental e serviço social: o desafio da subjetividade e da interdiciplinariedade. São Paulo: Cortez, 2002.

BOBBIO, Norberto. Estado, governo, sociedade: por uma teoria geral da política. Rio de Janeiro: Paz e Terra, 1987.

CECÍlIO, Luiz Carlos de Oliveira. Autonomia versus controle dos trabalhadores: a gestão do poder no hospital. Revista Ciência \& Saúde Coletiva, v. 4, n. 2, p. 315-329, 1999.

CONFERÊNCIA NACIONAL DE SAÚDE MENTAL: Cuidar, sim. Excluir, não. 3., 2002, Brasília. Caderno Informativo. Brasília: Ministério da Saúde, 2002. (Série de Reuniões e Conferências; n.15).

CUNHA, Edite da Pena; CUNHA, Eleonora Schettini M. Políticas públicas sociais. In: CARVALHO, Alysson et al. (Org.). Políticas públicas. Belo Horizonte: UFMG, 2002. p. 11-25.

DAGNINO, Evelina (Org.). Sociedade civil e espaços públicos no Brasil. São Paulo: Paz e Terra, 2002.

DAGNINO, Evelina. Sociedade Civil, Espaços Públicos e a Construção Democrática no Brasil: Limites e Possibilidades. In: DAGNINO, Evelina (Org.). Sociedade civil e espaços públicos no Brasil. São Paulo: Paz e Terra, 2002. 
DRUMOND, Camila Zaina; CASARE, M. Giovana Sanches. CAPS: um novo modelo de assistência à Saúde Mental. 2002. Trabalho de Conclusão de Curso (Graduação em Serviço Social) Universidade Estadual de Londrina, Londrina.

FIGUEIREDO, Ana Elisa Bastos. Doença mental: exigência de integração e coerência. Informação Psiquiátrica, Rio de Janeiro, v. 1, n. 18, p. 23-28, 1999.

FIRMO, Bianca Rodrigues. Reforma psiquiátrica: impressões e expressões dos técnicos do caps Londrina. 2003. Trabalho de Conclusão de Curso (Graduação em Serviço Social) - Universidade Estadual de Londrina.

FOUCAULT, Michel. A Arqueologia do Saber. Rio de Janeiro: Forense Universitária, 2004.

FOUCAULT, Michel. A crise atual da medicina. Rio de Janeiro, 1974. Palestra pronunciada no Instituto de Medicina Social da Universidade do Estado do Rio de Janeiro.

FOUCAULT, Michel. História da loucura. São Paulo: Perspectiva, 1999.

FOUCAULT, Michel. O sujeito e o poder. In: RABINOW, P.; DREYFUS, H. Michel Foucault, uma trajetória filosófica (Para além do estruturalismo e da hermenêutica). Rio de Janeiro: Forense Universitária, 1995. p. 231-249.

FOUCAULT, Michel. Vigiar e punir: nascimento da prisão. Rio de Janeiro: Vozes, 1987.

FOUCAULT, Michel. Os anormais. São Paulo: Martins Fontes, 2002.

GOFFMAN, Erving. Manicômios, prisões e conventos. São Paulo: Perspectiva, 2003.

MACHADO, R. Por uma genealogia do poder. In: FOUCAULT, M. Microfísica do Poder. Rio de Janeiro: Graal, 1979. p. vii-xxiii.

MAIA, Rousiley C. M.; FERNANDES, Adélia B. 0 movimento antimanicomial como agente discursivo na esfera pública política. Revista Brasileira de Ciências Sociais, v. 17, n. 48, p. 157-171, 2002.

MEDEIROS, Soraya Maria de; GUIMARÃES, Jacileide. Cidadania e saúde mental no Brasil: contribuições ao debate. Revista Ciência \& Saúde Coletiva, v. 7, n. 3, p. 571-579, 2002.

MUNÕZ, Cristina S. Hannab Arendt: el espacio de la Política. Madrid: Centro de Estudos Políticos y Constitucionales, 2003.

ORGANIZAÇÃO MUNDIAL DA SAÚDE, ORGANIZAÇÃO PAN-AMERICANA DA SAÚDE. Relatório sobre a saúde no mundo 2001: Saúde mental: nova concepção, nova esperança. Rio de Janeiro: Gráfica BRASIL, 2001.

PASSOS, Izabel Christina Friche; BEATO, Mônica Soares da Fonseca. Concepções e Práticas Sociais em torno da Loucura: alcance e atualidade da História da Loucura de Foucault para investigação etnográficas. Psychê, São Paulo, ano 7, n. 12, p. 137-158, jul-dez. 2003.

PESSOTTI, Isaias. A loucura e as épocas. São Paulo: Ed.34, 1994.

PESSOTTI, Isaias. O século dos manicômios. São Paulo: Ed. 34,1996. 
PESSOTTI, Isaias. Os nomes da loucura. São Paulo: Ed. 34, 1999.

PEY, Maria Oly; BACCA, Ana Maria; SÀ, Raquel Stela de. Naspegadas de Foucault: apontamentos para a pesquisa em instituições. Rio de Janeiro: Achiamé,2004.

RABINOW, Paul; DREYFUS, Hubert. Michel Foucault, uma trajetória filosófica (Para além do estruturalismo e da hermenêutica). Rio de Janeiro: Forense Universitária, 1995.

RESENDE, Heitor: Política de saúde mental no Brasil: uma visão histórica. In: TUNDIS, Silvério Almeida; COSTA, Nilson do Rosário. Cidadania e Loucura, políticas de saúde mental no Brasil. Rio de Janeiro: Vozes, 2001. p. 15-73.

SCHWARCZ, Lilia Moritz. O espetáculo das raças: cientistas, instituições e questão racial no Brasil - 1870-1930. São Paulo: Companhia das Letras, 1993.

SERRANO, Alan Índio. O que é psiquiatria alternativa. São Paulo: Brasiliense, 1988.

SZASZ, Thomas S. 0 mito da doença mental. Rio de Janeiro: Zahar, 1979.

TEIXEIRA, Manuel Olavo Loureiro. Nascimento da Psiquiatria no Brasil. Cadernos IPUB, Rio de Janeiro, n. 8, p. 42-78, 1997.

VASCONCELOS, Eduardo Mourão. Breve Periodização Histórica do Processo de Reforma Psiquiátrica no Brasil Recente. In: ROSA, Lúcia Cristina dos Santos; PEREIRA, Ivana Carla Garcia; BISNETO, José Augusto; VASCONSELOS, Eduardo Mourão (0rg.). Sanide mental e serviço social: o desafio da subjetividade e da interdiciplinariedade. São Paulo: Cortez, 2002. p. 19-34. 